\title{
Synthesis and Crystal Structures of Di-nuclear Zinc(II) Diphenate Complexes with 1,10-Phenanthroline and 2,2'-Bipyridine
}

\author{
Bon Kweon Koo \\ Department of Chemistry, Catholic University of Daegu, Gyeongbuk 712-702,Korea. E-mail: bkkoo@cu.ac.kr \\ Received May 12, 2011, Accepted June 24, 2011
}

\begin{abstract}
Two new $\mathrm{Zn}(\mathrm{II})$ complexes, $\left[\mathrm{Zn}_{2}(\mathrm{dpa})_{2}(\text { phen })_{2}\left(\mathrm{H}_{2} \mathrm{O}\right)_{2}\right] \cdot \mathrm{H}_{2} \mathrm{O}(\mathbf{1})(\mathrm{dpa}=$ dephenate, phen = 1,10-phenanthroline $)$ and $\left[\mathrm{Zn}_{2}(\mathrm{dpa})_{2}(\mathrm{bpy})_{2}\left(\mathrm{H}_{2} \mathrm{O}\right)_{2}\right](2)\left(\mathrm{bpy}=2,2^{\prime}\right.$-bipyridine $)$ have been synthesized and characterized by elemental analysis, infrared spectroscopy, thermogravimetric analysis, and single crystal X-ray diffraction. The X-ray analysis reveals that the structures of $\mathbf{1}$ and $\mathbf{2}$ are dinuclear zinc(II) complexes bridged by dpa dianions, respectively. The zinc ions in $\mathbf{1}$ exhibit a distorted square pyramidal environments, while the zinc ions in $\mathbf{2}$ exhibit a trigonal bipyramid geometry. In each complex, the dpa ligand is coordinated to zinc ions as a bismonodentate.
\end{abstract}

Key Words : Dinuclear zinc(II) complexes, Diphenate, Crystal structure, Thermal properties

\section{Introduction}

Recently much attention has been paid to design and synthesis of metal-organic hybrid materials with fascinating network topologies ${ }^{1-3}$ and potential applications as functional materials. ${ }^{4-8}$ The most commonly used strategy for designing such materials relies on the utilization of multidentate $\mathrm{N}$ - or O-donor ligands which have the capacity to bridge between metal centers to form polymeric structures. Multi-carboxylate ligands, especially dicarboxylate ligands, have been extensively used to form metal-organic frameworks (MOF), in which rigid multi-carboxylate ligands, such as 1,2-benzene dicarboxylate, 1,3-benzenedicarboxylate, 1,4-benzenedicarboxylate, 1,2,4-benzene tricarboxylate, and 1,3,5-benzene tricarboxylate, have been used as a building block to construct some porous coordination frameworks. ${ }^{9-11}$ In contrast to the rigid aromatic multi-carboxylate anions, the aliphatic $\alpha, \omega$-dicarboxylate ligands as important flexible spacer ligands due to their conformational and coordination versatility tend to bridge transition metal ions to form coordination polymers with a variety of interesting structures. ${ }^{12-14}$

Diphenic acid is a useful source possessing several novel features besides its metrics of aromatic dicarboxylate ligands. It has 2,2'-positioned carboxyl groups with the steric hindrance, and two phenyl rings are not coplanar. The carboxyl groups can partly or entirely deprotonated, which makes it possible to coordinating with metal ion or forming hydrogen bonding interactions. Many frameworks constructed by $\mathrm{dpa}^{2-}$ or $\mathrm{Hdpa}^{-}$with transition metal ions or rare earth ions have been reported, mainly using hydrothermal synthetic method. ${ }^{15-20}$ Also, the auxiliary ligands, such as 1,10-phenanthroline or 2,2'-bipyridine, have obvious great effect on the structures of complexes. The combination of the metal ion and above-mentioned two types of bridging and auxiliary ligands can generate some unique structural motifs, which cannot be obtained only through one type of ligands.

In view of these factors, we explored the self-assembly of $\mathrm{Zn}$ (II) ion, $\mathrm{H}_{2}$ dpa, and pnen/bpy under hydrothermal conditions, and obtained two crystalline complexes: $\left[\mathrm{Zn}_{2}(\mathrm{dpa})_{2}-\right.$ (phen $\left.)_{2}\left(\mathrm{H}_{2} \mathrm{O}\right)_{2}\right] \cdot \mathrm{H}_{2} \mathrm{O}$ (1) and $\left[\mathrm{Zn}_{2}(\mathrm{dpa})_{2}(\text { bpy })_{2}\left(\mathrm{H}_{2} \mathrm{O}\right)_{2}\right]$ (2). These discrete units were further extended into supramolecular framework by hydrogen bonds and $\pi-\pi$ stacking interactions. Herein, we report the synthesis, crystal structures, and thermal properties of two new zinc(II) complexes.

\section{Experimental}

Chemicals and Measurements. All chemicals are commercially available and were used as received without further purification. Elemental analyses $(\mathrm{CHN})$ were performed on a Vario EL EA-Elementar Analyzer. Infrared spectra were recorded in the range from 4000 to $400 \mathrm{~cm}^{-1}$ on a Mattson Polaris FT-IR Spectrophotometer using $\mathrm{KBr}$ pellets. Thermogravimetric (TG) and differential thermal analysis (DTA) were performed on a Shimadzu DTG-60 instrument with a heating rate of $10^{\circ} \mathrm{C} \cdot \mathrm{min}^{-1}$.

Preparation of $\left[\mathrm{Zn}_{2}(\text { dpa })_{2}(\text { phen })_{2}\left(\mathrm{H}_{2} \mathrm{O}\right)_{2}\right]\left(\mathrm{H}_{2} \mathrm{O}\right)$ (1). A mixture of $\mathrm{Zn}(\mathrm{OAc})_{2} \cdot 2 \mathrm{H}_{2} \mathrm{O}(0.033 \mathrm{~g}, 0.15 \mathrm{mmol}), \mathrm{H}_{2} \mathrm{dpa}$ $(0.037 \mathrm{~g}, 0.15 \mathrm{mmol})$, phen $(0.025 \mathrm{~g}, 0.15 \mathrm{mmol}), \mathrm{NaOH}$ $(0.1 \mathrm{~mL}, 0.65 \mathrm{M}), 10 \mathrm{~mL} \mathrm{H}_{2} \mathrm{O}$ and $1 \mathrm{~mL}$ ethanol was placed in a $23 \mathrm{~mL}$ Teflon-lined stainless steel autoclave, and the vessel was heated to $120{ }^{\circ} \mathrm{C}$ for 3 days. The resulting colorless block crystals were filtered off and washed with water and then dried at room temperature. Yield 75\% (0.059 g) based on $\mathrm{Zn}$. Anal. Calcd. for $\mathrm{C}_{52} \mathrm{H}_{38} \mathrm{~N}_{4} \mathrm{O}_{11} \mathrm{Zn}_{2}$ : C, 60.89; H, 3.73; N, 5.46. Found: C, 61.05; H, 3.96; N, 5.46\%. IR $\left(\mathrm{KBr}\right.$ pellet, $\left.\mathrm{cm}^{-1}\right): 3589(\mathrm{w}), 3476(\mathrm{w}), 3060(\mathrm{w}), 1615(\mathrm{~s})$, 1564(m), 1519(m), 1429(m), 1356(s), 1147(m), 847(m), 809(m), 780(m), 724(m).

Preparation of $\left[\mathrm{Zn}_{2}(\mathrm{dpa})_{2}(\mathrm{bpy})_{2}\left(\mathrm{H}_{2} \mathrm{O}\right)_{2}\right]$ (2). The compound was prepared similarly by the method described above for the preparation of $\mathbf{1}$, with use of 2,2'-bpy instead 
Table 1. Crystal data and structure refinement for complexes $\mathbf{1}$ and

\begin{tabular}{|c|c|c|}
\hline Complex & 1 & 2 \\
\hline Empirical formula & $\mathrm{C}_{52} \mathrm{H}_{38} \mathrm{~N}_{4} \mathrm{O}_{11} \mathrm{Zn}_{2}$ & $\mathrm{C}_{48} \mathrm{H}_{36} \mathrm{~N}_{4} \mathrm{O}_{10} \mathrm{Zn}_{2}$ \\
\hline Formula weight & 1025.61 & 959.55 \\
\hline $\mathrm{T}(\mathrm{K})$ & $200(2)$ & $200(2)$ \\
\hline$\lambda(\AA)$ & 0.71073 & 0.71073 \\
\hline Crystal system & Triclinic & monoclinic \\
\hline Space group & P-1 & $\mathrm{P} 2(1) / \mathrm{c}$ \\
\hline$a(\AA)$ & $8.1206(6)$ & $10.9366(7)$ \\
\hline$b(\AA)$ & $11.7188(10)$ & $9.4322(6)$ \\
\hline$c(\AA)$ & $12.6303(10)$ & $20.5141(14)$ \\
\hline$\alpha\left({ }^{\circ}\right)$ & $106.947(2)$ & \\
\hline$\beta\left(^{\circ}\right)$ & $104.728(2)$ & $104.590(2)$ \\
\hline$\gamma\left(\left(^{\circ}\right)\right.$ & $97.638(2)$ & \\
\hline$V\left(\AA^{3}\right)$ & $1083.78(15)$ & $2047.9(2)$ \\
\hline $\mathrm{Z}$ & 1 & 2 \\
\hline$\mu\left(\mathrm{mm}^{-1}\right)$ & 1.179 & 1.240 \\
\hline$F(000)$ & 524 & 984 \\
\hline$\theta\left(^{\circ}\right)$ & 1.77 to 28.31 & 1.92 to 28.29 \\
\hline Absorption correction & $\begin{array}{l}\text { multi-scan } \\
\mathrm{T}_{\min }=0.822, \\
\mathrm{~T}_{\max }=0.924\end{array}$ & $\begin{array}{l}\text { multi-scan } \\
\mathrm{T}_{\min }=0.796 \\
\mathrm{~T}_{\max }=0.904\end{array}$ \\
\hline Limiting indices & $\begin{array}{l}-8 \leq h \leq 10 \\
-15 \leq k \leq 13, \\
-16 \leq l<16\end{array}$ & $\begin{array}{l}-13 \leq h \leq 14, \\
-12 \leq k \leq 10 \\
-27 \leq l<27\end{array}$ \\
\hline Reflections collected & 8107 & 14861 \\
\hline Independent reflections & \multicolumn{2}{|c|}{$5308[\mathrm{R}(\mathrm{int})=0.0314] 5086[\mathrm{R}(\mathrm{int})=0.0785]$} \\
\hline $\begin{array}{l}\text { Observed reflections } \\
{[I \geq 2 \sigma(I)]}\end{array}$ & 3832 & 2924 \\
\hline Goodness-of-fit on $F^{2}$ & 1.149 & 1.096 \\
\hline$R_{1}[I \geq 2 \sigma(I)]$ & 0.0676 & 0.0571 \\
\hline$w R_{2}[I \geq 2 \sigma(I)]$ & 0.1274 & 0.0888 \\
\hline$R_{1}$ & 0.1191 & 0.1296 \\
\hline$w R_{2}$ & 0.1962 & 0.1352 \\
\hline Largest peak and hole (e£ & ) 1.778 and -2.569 & 1.091 and -1.801 \\
\hline
\end{tabular}

of phen. Yield 57\% (0.042 g) based on $\mathrm{Zn}$. Anal. Calcd. for $\mathrm{C}_{48} \mathrm{H}_{36} \mathrm{~N}_{4} \mathrm{O}_{10} \mathrm{Zn}_{2}$ : C, 60.08; H, 3.78; N, 5.84. Found: C, 60.03; H, 4.01; N, 5.82\%. IR (KBr pellet, $\left.\mathrm{cm}^{-1}\right): 3680(\mathrm{~m})$, 2973(s), 1631(m), 1552(m), 1442(m), 1390(m), 1334(m), 1056(s), 1033(s), 1013(m), 774(m), 752(m).

X-ray Structure Determination. Single crystals of $\mathbf{1}$ and 2 were obtained by the method described in the above procedures. Structural measurement for the two complexes were performed on a Bruker SMART APEX CCD diffractometer using graphite monochromatized Mo-K $\alpha$ radiation $(\lambda$ $=0.71073 \AA$ ) at the Korea Basic Science Institute. A multiscan absorption correction was applied using the SADABS program. ${ }^{21}$ The structures were solved by direct method and refined on $F^{2}$ by full-matrix least-squares procedures using the SHELXTL programs. ${ }^{22}$ All non-hydrogen atoms were refined using anisotropic thermal parameters. $\mathrm{CH}$ hydrogen atoms were included in the structure factor calculation at idealized positions by using a riding model, but not refined. Images were created with the $\mathrm{ORTEP}^{23}$ or DIAMOND pro- gram. ${ }^{24}$ The crystallographic data for complexes $\mathbf{1}$ and $\mathbf{2}$ are listed in Table 1

\section{Results and Discussion}

Description of the Structures. The structure of 1 consists of dinuclear species, $\left[\mathrm{Zn}_{2}(\mathrm{dpa})_{2}(\mathrm{phen})_{2}\left(\mathrm{H}_{2} \mathrm{O}\right)_{2}\right]$ and one lattice water (Fig. 1(a)). In the dinuclear unit, each zinc(II) ion exhibits a distorted square pyramidal environments with $\tau=0.43\left[\tau=|\beta-\alpha| / 60^{\circ}\right]$, where $\beta$ and $\alpha$ are the two largest angles around the central atom; $\tau=0$ and 1 for the perfect square pyramidal and trigonal bipyramidal geometries, respectively. ${ }^{25,26}$ Two nitrogen atoms from one chelating ligand phen and two oxygen atoms from one dpa and one coordinated water define the basal plane, where the apical position is occupied by an another dpa ligand oxygen. The basal plane (N1N2O1O5) is nearly planar (mean deviation $0.242(5) \AA$ ) and the $\mathrm{Zn} 1$ is displaced by $0.537(1) \AA$ from the plane toward $3^{\mathrm{i}}$. The structural data (Table 2) are in agreement with those of the zinc(II) complexes which exhibit the similar geometry. ${ }^{27-29}$

The dpa ligand adopts bis-monodentate coordination mode and shows cis-configuration (see Scheme 1(a)). Two dpa ligands link two $\mathrm{Zn}(\mathrm{II})$ atoms $\left(\mathrm{Zn} 1 \cdots \mathrm{Zn} 1^{\mathrm{i}}=4.719(1) \AA\right)$, forming a cyclic dimer. (a)

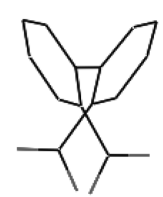

(b)

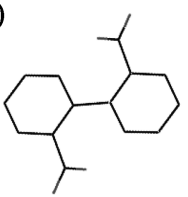

Scheme 1. The coordination modes of dpa ligand.

Two planes [C20-C25 and C14-C19] in dpa are nearly planar with mean deviation of $0.007(7) \AA$, respectively, the dihedral angle between the two planes being $81.8(2)^{\circ}$. The $\mathrm{O} 1-\mathrm{C} 13$ bond length is somewhat longer than the $\mathrm{O} 2-\mathrm{C} 13$ as expected from oxygen $\mathrm{O} 1$ involved in coordination (Table 2 ). The phen molecules are also nearly planar [the largest deviation of atoms from the mean plane is $\mathrm{C} 2$ atom, $-0.078(8) \AA]$, the dihedral angles between the mean planes of three planes $(\mathrm{C} 1-\mathrm{C} 4 \mathrm{C} 12 \mathrm{~N} 1, \mathrm{C} 4-\mathrm{C} 7 \mathrm{C} 11 \mathrm{C} 12$, and $\mathrm{C} 7-$ $\mathrm{C} 11 \mathrm{~N} 2$ ) being $1.6(2)-4.1(2)^{\circ}$. In the complex, two phen ligands are trans oriented to each other. The intra-ring $\mathrm{C}-\mathrm{N}$ [mean value: $1.333(8) \AA$ ] and $\mathrm{C}-\mathrm{C}$ [mean value; $1.401(9) \AA$ for phen and 1.411(9) $\AA$ for dpa] bond distances are as expected. ${ }^{30,31}$

The dinuclear units are further stabilized by the intramolecular hydrogen bonds involving the coordinated water molecules and carboxylate oxygen atoms (coordinated) [O5-H5 ․ O3] (Fig. 1(b)). In addition, intermolecular hydrogen bonds $(\mathrm{C}-\mathrm{H} \cdots \mathrm{O})$ are also observed between the phen molecules and the oxygen atoms of the carboxylates and between dpa ligands. The hydrogen bonds (C6-H6 $\cdots \mathrm{O} 2$ and C8-H8 $\cdots \mathrm{O} 2$ ) between phen molecule and carboxylate oxygen form 1D chain network along c-axis, which is further 
Table 2. Selected bond lengths $(\AA)$ and angles $\left({ }^{\circ}\right)$ for complex 1 and 2

\begin{tabular}{|c|c|c|c|}
\hline \\
\hline \multicolumn{4}{|l|}{$\begin{array}{l}\text { Complex } 1 \\
\text { Zn1-O1 }\end{array}$} \\
\hline $\mathrm{Zn} 1-\mathrm{O} 5$ & $2.113(4)$ & Zn1-N1 & $2.115(5)$ \\
\hline $\mathrm{Zn} 1-\mathrm{N} 2$ & $2.142(5)$ & $\mathrm{O} 1-\mathrm{C} 13$ & $1.290(7)$ \\
\hline $\mathrm{O} 2-\mathrm{C} 13$ & $1.237(7)$ & $\mathrm{O} 3-\mathrm{C} 26$ & $1.287(8)$ \\
\hline $\mathrm{O} 4-\mathrm{C} 26$ & $1.220(8)$ & & \\
\hline $\mathrm{O} 3^{\mathrm{i}}-\mathrm{Zn} 1-\mathrm{O} 1$ & $95.36(18)$ & $\mathrm{O} 3^{\mathrm{i}}-\mathrm{Zn} 1-\mathrm{O} 5$ & $95.58(18)$ \\
\hline $\mathrm{O} 1-\mathrm{Zn} 1-\mathrm{O} 5$ & $88.81(17)$ & $\mathrm{O}^{\mathrm{i}}-\mathrm{Zn} 1-\mathrm{N} 1$ & $102.13(19)$ \\
\hline O1-Zn1-N1 & $162.51(18)$ & O5-Zn1-N1 & 89.93(19) \\
\hline $\mathrm{O} 3^{\mathrm{i}}-\mathrm{Zn} 1-\mathrm{N} 2$ & $127.9(2)$ & $\mathrm{O} 1-\mathrm{Zn} 1-\mathrm{N} 2$ & $91.09(19)$ \\
\hline O5-Zn1-N2 & $136.27(19)$ & $\mathrm{N} 1-\mathrm{Zn} 1-\mathrm{N} 2$ & $77.9(2)$ \\
\hline $\mathrm{O} 2-\mathrm{C} 13-\mathrm{O} 1$ & $123.0(5)$ & $\mathrm{O} 4-\mathrm{C} 26-\mathrm{O} 3$ & $124.1(6)$ \\
\hline
\end{tabular}

Symmetry codes: i) 1-x, 1-y, 2-z

Complex 2

\begin{tabular}{llll}
$\mathrm{Zn} 1-\mathrm{O} 1$ & $1.981(3)$ & $\mathrm{Zn} 1-\mathrm{O} 3^{\mathrm{i}}$ & $1.999(3)$ \\
$\mathrm{Zn} 1-\mathrm{O} 5$ & $2.119(4)$ & $\mathrm{Zn} 1-\mathrm{N} 1$ & $2.155(4)$ \\
$\mathrm{Zn} 1-\mathrm{N} 2$ & $2.114(4)$ & $\mathrm{O} 1-\mathrm{C} 11$ & $1.288(6)$ \\
O2-C11 & $1.226(6)$ & $\mathrm{O} 3-\mathrm{C} 24$ & $1.272(6)$ \\
O4-C24 & $1.257(6)$ & & \\
O3 $3^{\mathrm{i} Z n 1-O 1}$ & $121.54(14)$ & $\mathrm{O} 3^{\mathrm{i}}-\mathrm{Zn} 1-\mathrm{O} 5$ & $86.64(14)$ \\
O1-Zn1-O5 & $95.82(14)$ & $\mathrm{O} 3^{\mathrm{i}}-\mathrm{Zn} 1-\mathrm{N} 1$ & $94.16(15)$ \\
O1-Zn1-N1 & $95.34(15)$ & $\mathrm{O} 5-\mathrm{Zn} 1-\mathrm{N} 1$ & $166.37(15)$ \\
O3 $3^{\mathrm{i}} \mathrm{Zn} 1-\mathrm{N} 2$ & $115.28(15)$ & $\mathrm{O} 1-\mathrm{Zn} 1-\mathrm{N} 2$ & $123.07(15)$ \\
O5-Zn1-N2 & $90.48(15)$ & $\mathrm{N} 1-\mathrm{Zn} 1-\mathrm{N} 2$ & $76.85(17)$ \\
O2-C11-O1 & $123.1(5)$ & $\mathrm{O} 4-\mathrm{C} 24-\mathrm{O} 3$ & $124.0(5)$ \\
\hline
\end{tabular}

Symmetry codes: i) 1-x, 1-y, -z

stabilized by the inter-phen ring $\pi-\pi$ stacking (interplanar distance is $3.665 \AA$ ) (Fig. 1(b)). ${ }^{32}$ The hydrogen bond between dpa ligands, C24-H24 $\cdots \mathrm{O} 4$ links the dimers into 1D chain along b-axis, to form 2D network (bc-plane). While, the hydrogen bonds, $\mathrm{C} 2-\mathrm{H} 2 \cdots \mathrm{O} 3$ and $\mathrm{C} 16-\mathrm{H} 16 \cdots \mathrm{O} 2$ bring the formation of 3D supramolecular network (Fig. 1(c)). The details of hydrogen bonds are listed in Table 3.

Complex 2 is also composed of a dimer. The asymmetric unit of 2 consists of a $\mathrm{Zn}$ (II) ion, one dpa ligand, one bpy ligand and one water molecule. Each $\mathrm{Zn}$ (II) ion is located in an distorted trigonal bipyramidal geometry $(\tau=0.72)$ in which the equatorial positions are occupied by the $\mathrm{O} 1, \mathrm{O} 3$, $\mathrm{N} 2$ and the axial positions by $\mathrm{O} 5$ and N1 with the O5-Zn1$\mathrm{N} 1$ angle of $166.37(15)^{\circ}$ showing the large deviation from an ideal value of $180^{\circ}$ (Fig. 2(a)). The average $\mathrm{Zn}-\mathrm{N}$ bond length is $2.135(4) \AA$, longer than the average $\mathrm{Zn}-\mathrm{O}$ distance $(2.033(3) \AA)$ (Table 2). These structural data are in agreement with those of the zinc(II) complex, $\mathrm{Zn}_{2}$ (DPA) $)_{2}$ (mbix)$\left(\mathrm{H}_{2} \mathrm{O}\right)(\mathrm{mbix}=1,3 \text {-bis(imidazol-1-ylmethyl)benzene })^{33}$ which exhibit the similar formula. The zinc(II) ions bridged by the dpa in a bis-monodentate fashion are separated by 4.544(1) $\AA$. Each $\mathrm{Zn}(\mathrm{II})$ ion is slightly displaced $(0.039(1) \AA)$ from the equatorial plane toward the O5. Other structural data are also similar to the values of complex 1 .

The dinuclear units are interconnected through intra-and inter-molecular hydrogen bonds and $\pi-\pi$ stacking interaction.
Table 3. Parameters $\left(\AA,{ }^{\circ}\right)$ for hydrogen-bonding interaction of complex 1 and $\mathbf{2}$

\begin{tabular}{lcccc}
\hline Donor-H $\cdots$ acceptor & $\mathrm{D}-\mathrm{H}$ & $\mathrm{H} \cdots \mathrm{A}$ & $\mathrm{D} \cdots \mathrm{A}$ & $\mathrm{D}-\mathrm{H} \cdots \mathrm{A}$ \\
\hline Complex 1 & & & & \\
$\mathrm{O} 5-\mathrm{H} 5 \mathrm{~A} \cdots \mathrm{O} 3$ & 0.98 & 2.21 & $3.08(1)$ & 147.9 \\
$\mathrm{C} 2-\mathrm{H} 2 \cdots \mathrm{O} 3{ }^{\mathrm{i}}$ & 0.95 & 2.83 & $3.57(1)$ & 135.3 \\
$\mathrm{C} 6-\mathrm{H} 6 \cdots \mathrm{O} 2^{\mathrm{ii}}$ & 0.95 & 2.99 & $3.71(1)$ & 132.8 \\
$\mathrm{C} 8-\mathrm{H} 8 \cdots \mathrm{O} 2^{\mathrm{ii}}$ & 0.95 & 2.33 & $3.20(1)$ & 152.9 \\
$\mathrm{C} 16-\mathrm{H} 16 \cdots \mathrm{O} 2^{\mathrm{iii}}$ & 0.95 & 2.57 & $3.56(1)$ & 140.9 \\
$\mathrm{C} 24-\mathrm{H} 24 \cdots \mathrm{O} 4{ }^{\text {iv }}$ & 0.95 & 2.48 & $3.32(1)$ & 146.6 \\
\hline
\end{tabular}

Symmetry codes: i) 2-x, 1-y, 2-z; ii) 1-x, 1-y, 1-z; iii) $-1+x, y, z$; iv) 1-x, $-\mathrm{y}, 2-\mathrm{z}$

\begin{tabular}{lllll}
\hline Complex 2 & & & & \\
$\mathrm{O}^{2}-\mathrm{H} 5 \mathrm{~B} \cdots \mathrm{O} 1^{\mathrm{i}}$ & 0.98 & 1.80 & $2.73(1)$ & 156.6 \\
$\mathrm{C} 1-\mathrm{H} 1 \cdots 4^{\mathrm{i}}$ & 0.95 & 2.48 & $3.17(1)$ & 129.9 \\
$\mathrm{C} 2-\mathrm{H} 2 \cdots \mathrm{O}^{\text {iii }}$ & 0.95 & 2.62 & $3.47(1)$ & 149.0 \\
$\mathrm{C} 4-\mathrm{H} 4 \cdots \mathrm{O} 2^{\mathrm{ii}}$ & 0.95 & 2.33 & $3.10(1)$ & 137.8 \\
$\mathrm{C} 7-\mathrm{H} 7 \cdots 4^{\mathrm{ii}}$ & 0.95 & 2.95 & $3.57(1)$ & 123.7 \\
$\mathrm{C} 8-\mathrm{H} 8 \cdots{ }^{\mathrm{ii}}$ & 0.95 & 2.89 & $3.54(1)$ & 126.3 \\
$\mathrm{C} 16-\mathrm{H} 16 \cdots \mathrm{O}^{\mathrm{iv}}$ & 0.95 & 2.84 & $3.50(1)$ & 127.2
\end{tabular}

Symmetry codes: i) 1-x, 1-y, -z; ii) 1-x, -1/2+y, 1/2-z; iii) x, -1-y, z; iv) $2-$ $\mathrm{x}, 1-\mathrm{y},-\mathrm{z}$.

There is intramolecular hydrogen bonds involving the coordinated water molecules and carboxylate oxygen atoms [O5-H5 ․ O1]. While, the dimeric units are interconnected through intermolecular hydrogen bonds between the bpy molecules and oxygen atoms of the carboxylates (uncoordinated) $(\mathrm{C} 1-\mathrm{H} 1 \cdots \mathrm{O} 4, \mathrm{C} 4-\mathrm{H} 4 \cdots \mathrm{O} 2, \mathrm{C} 7-\mathrm{H} 7 \cdots \mathrm{O} 4, \mathrm{C} 8-\mathrm{H} 8 \cdots$ O4) to give 1D chain along the c-axis (Fig. 2(b)). The 1D chain is further stabilized by inter-phen $\pi-\pi$ stacking interactions (interplanar distance (mean value) $=3.838 \AA]{ }^{32}$ The hydrogen bondings between the dpa ligands (C16-H16 $\cdots$ O3) link these 1D chains together to form 2D layer. The 2D network structure is also connected through hydrogen

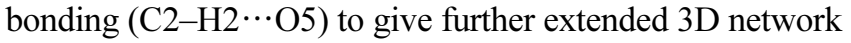
structure (Fig. 2(c)). The D $\cdots$ A bond distance and D-H $\cdots A$ angles are listed in Table 3.

IR Spectra. The IR spectra of the complexes $\mathbf{1}$ and $\mathbf{2}$ exhibit characteristic bands for the carboxylic groups of dicarboxylates. The strong bands assigned to asymmetric stretching vibration $v_{\text {as }}\left(\mathrm{COO}^{-}\right)$and symmetric stretching vibration $v_{\mathrm{s}}\left(\mathrm{COO}^{-}\right)$of the carboxylate groups are observed in the expected regions at 1615 and $1356 \mathrm{~cm}^{-1}$ for $\mathbf{1}$, and 1631 and $1334 \mathrm{~cm}^{-1}$ for 2 , respectively. ${ }^{34,35}$ The separations $\left(\Delta v=259\right.$ for 1 and $296 \mathrm{~cm}^{-1}$ for 2 ) between $v_{\text {as }}(\mathrm{COO})$ and $v_{\mathrm{s}}(\mathrm{COO})$ indicate the presence of monodendate mode in dpa, which are consistent with their crystal structures. ${ }^{36,37}$ The IR spectra also show the bands at 3589 (3680 for 2) and $3476 \mathrm{~cm}^{-1}$ corresponding to the vibration absorption of coordinated water and lattice water, respectively. ${ }^{38,39}$

Thermal Analysis. TG-DTA curves have been obtained in flowing $\mathrm{N}_{2}$ atmosphere for crystalline samples of $\mathbf{1}$ and $\mathbf{2}$ in the temperature range of $30-800{ }^{\circ} \mathrm{C}$ with a rate of $10{ }^{\circ} \mathrm{C}$ $\min ^{-1}$ (Fig. 3). The TG curves are divided into three stages. 
(a)

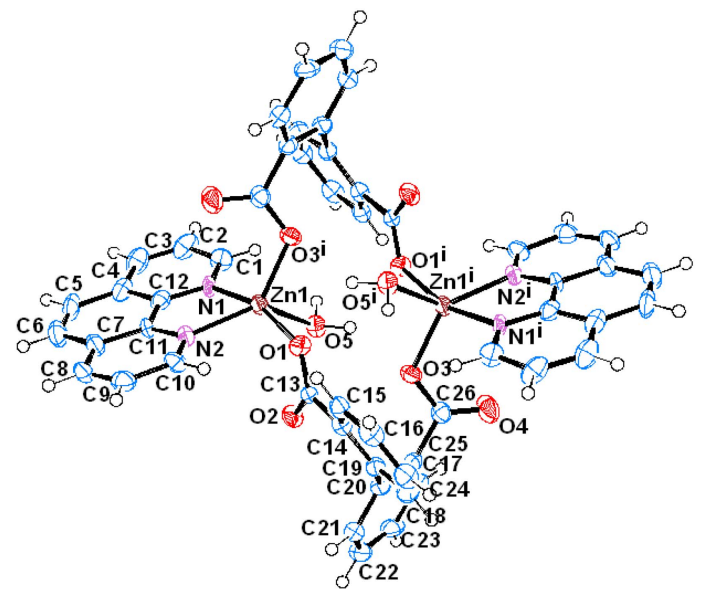

(b)

宣06

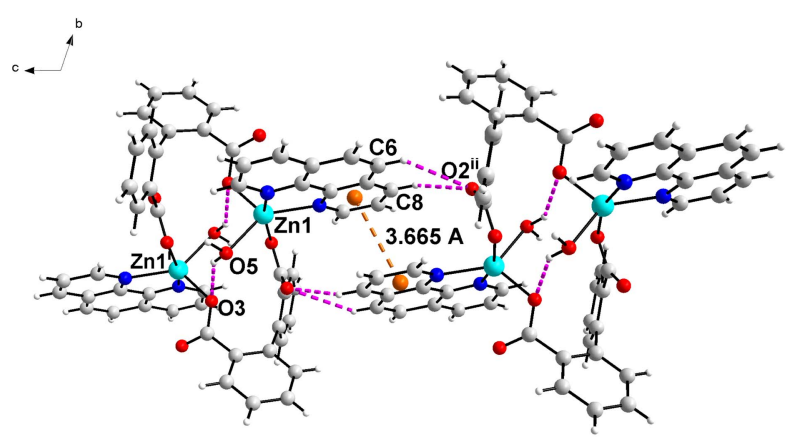

(c)

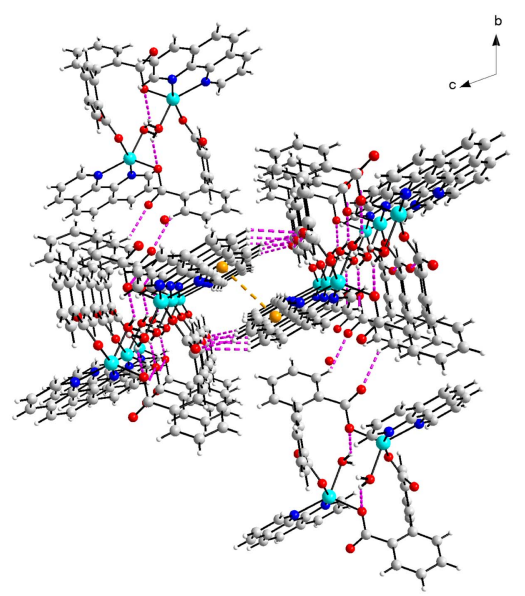

Figure 1. (a) Coordination environment of complex 1, showing $50 \%$ thermal ellipsoids and the atomic labeling. (b) $1 \mathrm{D}$ chain structure of complex 1 through hydrogen bonding and inter-phen $\pi-\pi$ Interactions (along c-axis). (c) Packing diagram of complex 1 viewed along a-axis. Symmetry codes: i) 1-x, 1-y, 2-z; ii) 1-x, 1-y, $1-\mathrm{z}$

For complex 1, the first weight loss of $5.67 \%$ between 97 and $174{ }^{\circ} \mathrm{C}$ with a sharp endothermic peak at $173{ }^{\circ} \mathrm{C}$ corresponds to the loss of one lattice and two coordinated water molecules per formula unit (calc. 5.27\%). Upon further heating up to $560{ }^{\circ} \mathrm{C}$, the anhydrous compositions show two indistinct weight loss stages with $80.27 \%$ in total (a)

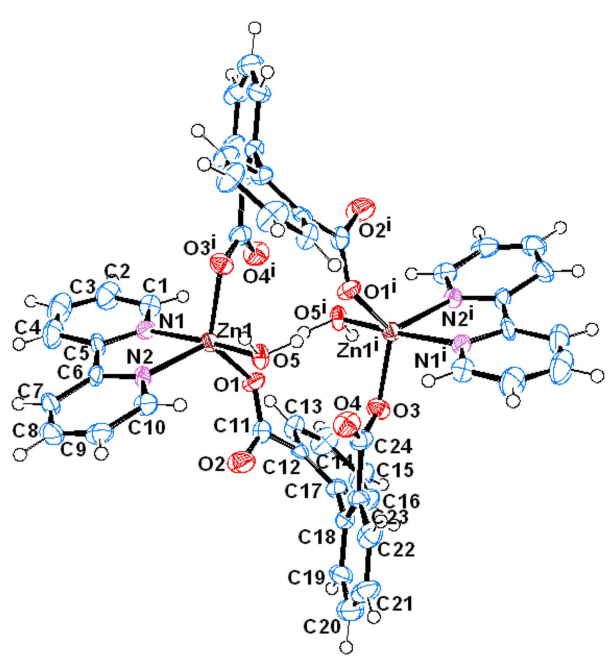

(b)

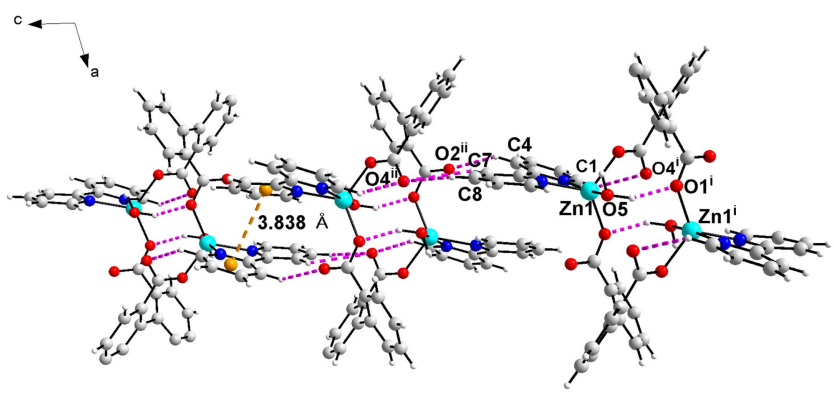

(c)

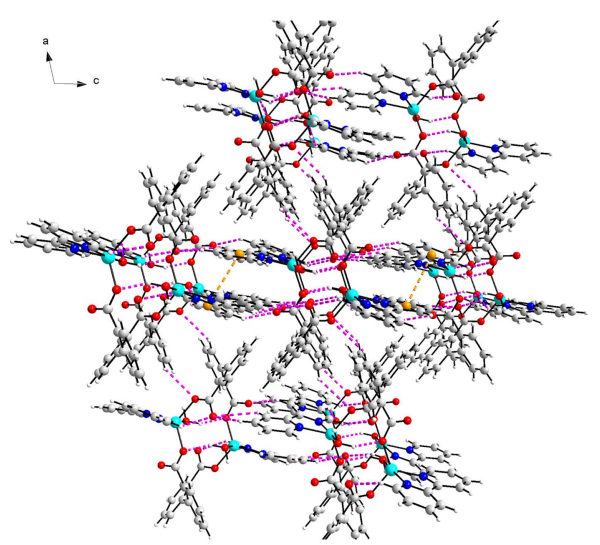

Figure 2. (a) Coordinatioin environment of complex 2, showing $50 \%$ thermal ellipsoids and the atomic labeling. (b) 1D chain structure of complex 2 through hydrogen bonding and inter-phen $\pi-\pi$ Interactions (along c-axis). (c) Packing diagram of complex 2 viewed along b-axis. Symmetry codes: i) 1-x, 1-y, -z; ii) ) 1-x, -1/ $2+y, 1 / 2-z$.

(calc. $81.98 \%$ ) corresponding to the decomposition of organic ligands. The final decomposed product presumably is attributed to $\mathrm{ZnO}$ (found $14.05 \%$. calc. $15.88 \%$ ). While, complex 2 shows the first weight loss of $3.90 \%$ (calc. $3.75 \%$ ) from 136 to $168^{\circ} \mathrm{C}$ with an endothermic peak at 163 ${ }^{\circ} \mathrm{C}$, which corresponds to the release of coordinated water 


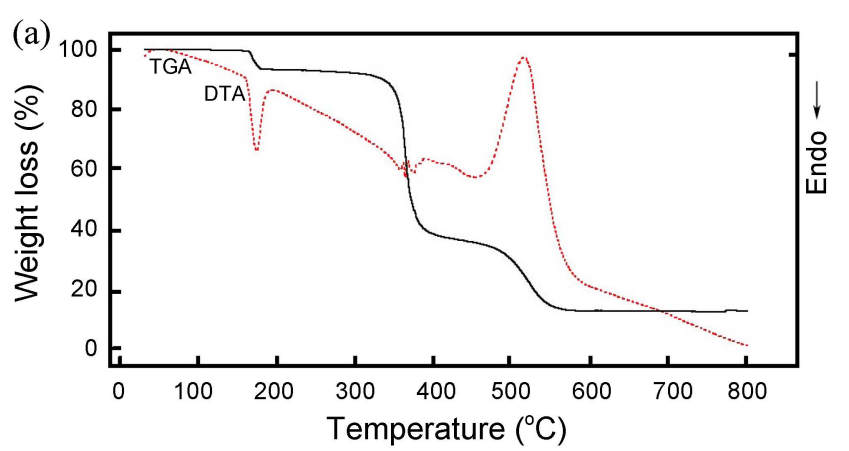

(b)

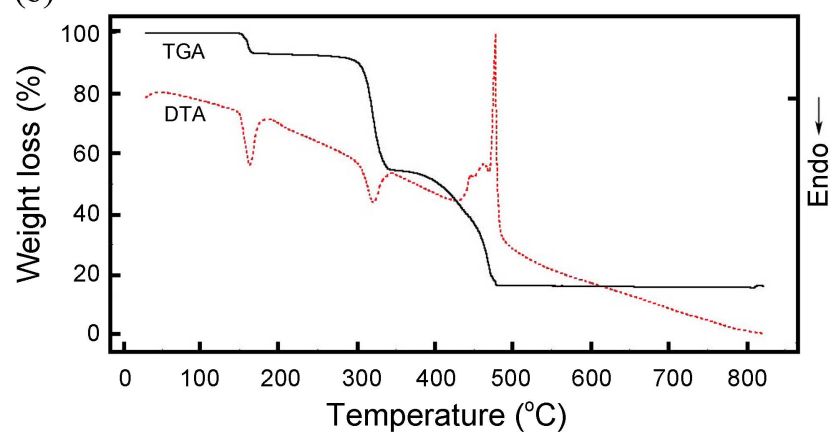

Figure 3. TG curves of complex 1 (a) and 2 (b).

molecule. Over $168-481{ }^{\circ} \mathrm{C}$, the sample loses the additional weight of $79.94 \%$ (calc. $82.61 \%$ ) corresponding to the decomposition of organic ligands in two steps overlapping to each other. These weight losses are accompanied by an endothermic and an exothermic effect on the DTA curve with maximum at 322 and $478^{\circ} \mathrm{C}$, respectively. The remaining weight corresponds to the formation of $\mathrm{ZnO}$ (obsd. $16.14 \%$, calc. $16.96 \%$ ).

\section{Conclusion}

We have synthesized two zinc(II) complexes $\mathbf{1}$ and $\mathbf{2}$ from the reaction mixture of $\mathrm{Zn}(\mathrm{OAc})_{2} \cdot 2 \mathrm{H}_{2} \mathrm{O}, \mathrm{H}_{2} \mathrm{dpa}$, phen/bpy, $\mathrm{NaOH}, \mathrm{H}_{2} \mathrm{O}$, and ethanol in the mole ratio 1.00:1.00:1.00: 4.33:370.37:10.39 at $120{ }^{\circ} \mathrm{C}$ by the hydrothermal reaction. The structures of $\mathbf{1}$ and $\mathbf{2}$ are dinuclear zinc(II) complexes bridged by dpa dianions, respectively. The zinc ions in $\mathbf{1}$ exhibit a distorted square pyramidal environments, while the zinc ions in $\mathbf{2}$ exhibit a trigonal bipyramid geometry. In each complex, the dpa ligand is coordinated to zinc ions as a bismonodentate. The dinuclear units of $\mathbf{1}$ and $\mathbf{2}$ are interconnected through intermolecular hydrogen bonds between the phen/bpy molecules and oxygen atoms of the carboxylates (coordinated and uncoordinated) to give 1D chain. In addition, both complexes show further extended 3D supramolecular network by the $\pi-\pi$ stacking as well as hydrogen bonding interaction. Although many interesting polymeric complexes containing the multi-carboxylate ligands have been reported, uncharacterized polymers were often obtained in hydrothermal reactions. Thus, the development of synthetic routes to the systems containing dicarboxylate is still required for the rational design and synthesis.
Supplementary Materials. Crystallographic data in CIF format have been deposited with the Cambridge Structural Database CCDC 825055 for $\mathbf{1}$ and 825056 for 2, respectively. These data can be obtained free of charge at www. ccdc.cam.ac.uk/conts/retrieving.html (or from the Cambridge Crystallographic Data Centre, 12, Union Road, Cambridge CB2 1EZ, UK; Fax: +44-1223/336-033; E-mail: deposit@, ccdc.cam.ac.uk).

Acknowledgments. This work was supported by the 2011 Research Fund of Catholic University of Daegu. The author also acknowledges the Korea Basic Science Institute for providing the crystal structure results.

\section{References}

1. Batten, S. R.; Robson, R. Angew. Chem. Int. Ed. 1998, 37, 1460.

2. Hagrman, P. J.; Hagrman, D.; Zubieta, J. Angew. Chem. Int. Ed. 1999, 38, 2638.

3. Carlucci, L.; Ciani, G.; Proserpio, D. Coord. Chem. Rev. 2003, $246,247$.

4. Jose, S.-V.; Mota, A. J.; Aouryaghal, H.; Cano, J.; RodriguezDieguez, A.; Luneau, D.; Colacio, E. Inorg. Chem. 2008, 47, 8143.

5. Liu, Y.; Hou, H.; Chen, Q.; Fan, Y. Cryst. Growth Des. 2008, 8, 1435.

6. Takaya, J.; Iwasawa, N. J. Am. Chem. Soc. 2008, 130, 15254.

7. Spencer, E. C.; Howard, J. A. K.; McIntyre, G. J.; Rowsell, J. L. C.; Yaghi, O. M. Chem. Commun. 2006, 278.

8. Ruben, M.; Rojo, J.; Romero-Salguero, F. J.; Uppadine, L. H.; Lehn, J.-M. Angew. Chem. Int. Ed. 2004, 43, 3644.

9. Cui, Y.; Lee, S. J.; Lin, W. J. Am. Chem. Soc. 2003, 125, 6014.

10. Horikoshi, R.; Mochida, T.; Moriyama, H. Inorg. Chem. 2002, 41, 3017.

11. Li, X.; Cao, R.; Sun, Y. Q.; Shi, Q.; Yuan, D. Q.; Sun, D. F.; Bi, W. H.; Hong, M. C. Cryst. Growth Des. 2004, 4, 225.

12. Kim, Y.; Jung, D. Y. Inorg. Chem. 2000, 39, 1470.

13. Bakalbassis, E. G.; Michailides, M. K. A.; Mrozinski, J.; Raptopoulou, C.; Skoulika, S.; Terzis, A.; Tsaousis, D. J. J. Chem. Soc., Dalton Trans. 2001, 6, 850.

14. Mukherjee, P. S.; Konar, S.; Zangrando, E.; Mallah, T.; Ribas, J.; Chaudhuri, N. R. Inorg. Chem. 2003, 42, 2695.

15. Shi, Q.; Sun, Y.; Sheng, L.; Ma, K.; Cai, X.; Liu, D. Inorg. Chim. Acta 2009, 362, 4167.

16. Karle, I. L.; Venkateshwarlu, P.; Nagaraj, R.; Sarma, A. V. S.; Vijay, D.; Sastry, N. G.; Ranganathan, S. Chem. Eur. J. 2007, 13, 4253.

17. Xu, X.; Lu, Y.; Wang, E.; Ma, Y.; Bai, X. J. Mol. Struct. 2006, 124.

18. Min, J.; Li, J.; Chen, W.; Zhang, F.-X. Struct. Chem. 2006, 17, 327.

19. Lu, J. Y.; Schauss, V. Inorg. Chem. Commun. 2003, 6, 1332.

20. Wang, R.; Zhou, Y.; Sun, Y.; Yuan, D.; Han, L.; Lou, B.; Wu, B.; Hong, M. Cryst. Growth Des. 2005, 5, 251.

21. Blessing, R. H. Acta Cryst. 1995, A51, 33.

22. Sheldrick, G. M. (2001). SHELXTL. Version 6. Bruker AXS Inc., Madison, Wisconsin, USA.

23. Farrugia, L. J. J. Appl. Cryst. 1997, 30, 565.

24. Brandenburg, K. DIAMOND. Version 2.1. Crystal Impact GbR, Bonn, Germany. 1998.

25. Addison, A. W.; Rao, T. N.; Reedijk, J.; van Rijn, J.; Verschoor, G. C. J. Chem. Soc., Dalton Trans. 1984, 1349.

26. Ray, A.; Banerjee, S.; Butcher, R. J.; Desplanches, C.; Mitra, S. Polyhedron 2008, 27, 2409.

27. Liu, G.-X.; Xu, Y.-Y.; Wanga, Y.; Nishihara, S.; Ren, X.-M. Inorg 
Chim. Acta 2010, 363, 3932.

28. Yin, P.-X.; Zhang, J.; Cheng, J.-K.; Li, Z.-J.; Yao, Y.-G. Inorg. Chem. Commun. 2006, 9, 541.

29. Huang, W.-W.; Yang, S.-P. Acta Cryst. 2008, E64, m525.

30. Koo, B. K.; Kim, J.; Lee, U. Inorg. Chim. Acta 2010, 363, 1760.

31. Kim, J.; Lee, U.; Koo, B. K. Bull. Korean Chem. Soc. 2010, 31, 1743.

32. Janiak, C. J. Chem. Soc., Dalton trans. 2000, 3885.

33. Liu, G.-X.; Zhu, K.; Xu, H.-M.; Nishihara, S.; Huang, R.-Y.; Ren, X.-M. CrystEngComm. 2009, 11, 2784.

34. Shao, M.; Li, M.-X.; Dai, H.; Lu, W.-C.; An, B.-L. J. Mol. Struct.
2007, 829, 155.

35. Wang, R.-H.; Gong, Y.-Q.; Han, L.; Yuan, D.-Q.; Lou, B.-Y.; Wu, B.-L.; Hong, M.-C. J. Mol. Struct. 2006, 784, 1.

36. Wang, R.; Yuan, D.; Jiang, F.; Han, L.; Gong, Y.; Hong, M. Cryst. Growth Des. 2006, 6, 1351.

37. Deacon, G. B.; Phillips, R. J. Coord. Chem. Rev. 1980, 33, 227.

38. Nakamoto, K. Infrared Spectra of Inorganic and Coordination Compounds, 4th ed., John Wiley \& Sons: New York, 1986; pp $228,371$.

39. Lazarou, K. N.; Chadjistamatis I.; Terzis, A.; Perlepes, S. P.; Raptopoulou, C. P. Inorg. Chim. Acta 2010, 363, 107. 